\title{
IMic - Mictório inteligente para auxilio no diagnóstico do câncer de próstata
}

\author{
Mariana Marques Ferreira ${ }^{1}$, Emmilly Raianny Bezerra Ferreira ${ }^{1}$, Maria Laysa \\ Meneses da Silva ${ }^{1}$, Marcos Nascimento Junior ${ }^{1}$, Maurício Rabello Silva ${ }^{1}$ \\ ${ }^{1}$ Instituto Federal da Paraíba (IFPB), Rua Presidente Tancredo Neves, s/n, Jardim \\ Sorrilândia, CEP 58.805-345 - Sousa - PB - Brasil \\ emmillyraianny@gmail.com, laysinhameneseslegmail.com, \\ mfmariana82@gmail.com, marcosnjunioregmail.com, \\ mauricio.silvadifpb.edu.br.
}

Resumo. O Mictório Inteligente é a combinação de duas áreas distintas, a saúde e informática, com o estudo e a interpretação de dados para realizar análises e fazer o diagnóstico de doenças através da urina. O público são pessoas do sexo masculino de 14 a 65 anos que estudem ou trabalhem em empresas e instituições públicas ou privadas. O sistema não substitui os exames de laboratório tradicionais, mas auxilia, através de um sistema computacional, embarcado em microcontroladores, capaz de automatizar a detecção de sintomas, ao fornecer avisos diários sobre a situação da saúde do sistema urinário do usuário que utilizará o IMic.

\section{Introdução}

O câncer de próstata é o segundo tipo mais comum entre os homens, atrás do câncer de pele não-melanoma. Para identificar este tumor, é realizado o exame de sangue de PSA (Antígeno Prostático Específico) ou o toque retal que são solicitados pelo urologista, quando se tem alguma suspeita ou até mesmo para fazer a prevenção. Porém, existe o preconceito entre os homens e muitos não fazem o exame de toque retal, por esse motivo muitos procuram o médico quando a doença está em um estágio avançado [INCA, 2016].

A Infecção do Trato Urinário (ITU), conhecida como Infecção Urinária, é uma doença que afeta indivíduos de ambos os sexos e de todas as idades, embora seja mais observada em mulheres. Esta patologia pode ocorrer em qualquer parte do sistema urinário, como rins, bexiga, uretra e ureteres, sendo mais frequente na bexiga e na uretra. Alguns sintomas são o aumento da frequência em que vão ao banheiro, alterações na coloração da urina entre outras manifestações.

Tendo em vista que estas doenças afetam a saúde do homem e a sua qualidade de vida, faz-se necessário desenvolver um sistema que possibilite realizar exames para identificar sintomas o quanto antes. Pensando neste problema, tivemos a ideia de desenvolver um mictório inteligente que faz uma análise básica da urina e exibe um aviso para o usuário procurar seu médico. 
Este trabalho apresenta uma possível solução para detectar indícios de alguns sintomas de câncer de próstata, através de exames de urina, realizados de forma automatizada. A seção 2 apresenta um resumo das doenças que afetam o sistema urinário. A seção 3 mostra os componentes do mictório inteligente. A seção 4 contém os resultados e discussões sobre o problema abordado e o IMic. As considerações finais e trabalhos futuros são apresentados na seção 5.

\section{Doenças que afetam o sistema urinário masculino}

O câncer de próstata é o quarto tipo mais frequente de câncer em e o segundo mais prevalente no sexo masculino em todo o mundo [Klein et al., 2007]. Esta neoplasia caracteriza-se pelo crescimento exagerado da próstata, com consequente diminuição do calibre e intensidade do jato urinário [Tonon e Schoffen, 2009].

Ainda conforme Tonon e Schoffen (2009), estão associadas ao surgimento desta doença influências genéticas, a história sexual, exposição a patógenos, substâncias químicas industriais, urbanização, hábitos alimentares, metabolismo hormonal, além da idade e do estilo de vida do paciente. Segundo Souza et al. (2013,) a grande dificuldade de constatação deste tumor deve-se ao fato de que na fase inicial o Câncer de Próstata se desenvolve de forma assintomática, ou seja, não apresenta sintomas específicos, evoluindo de forma silenciosa.

\section{IMic - Mictório Inteligente}

O protótipo do Mictório tem como finalidade detectar indícios de alguns sintomas de câncer de próstata e outras doenças renais a partir da coloração, do fluxo e também do volume da urina, e até mesmo da frequência em que um usuário utiliza o banheiro.

O IMic possui um placa Arduino que foi programada em uma linguagem própria desta plataforma, similar a $\mathrm{C} / \mathrm{C}++$. $\mathrm{O}$ sistema de controle mede quantidade e detecta percentuais da coloração da urina a partir de um medidor de volume e um sensor de coloração instalado em um local estratégico do mictório. O resultado das análises será apresentado em um display que ficará visível para o usuário no banheiro. Dessa maneira, depois de fazer as suas necessidades fisiológicas, o usuário recebe uma mensagem sobre a atual situação de sua urina.

A parte eletrônica possui uma placa com um microcontrolador Arduino que gerencia todos os outros componentes apresentados a seguir: sensor de cor, modelo RGB TCS34725; chave óptica CTK C860TP, para controlar um pluviômetro de báscula; pluviômetro de báscula utilizado para medir o volume da urina; display com a função de apresentar os dados processados pelo sistema do Mictório Inteligente - IMic.

\subsection{Componentes utilizado na construção do IMic.}


O processamento e controle dos periféricos do IMic foi utilizado um Arduino, sendo este uma plataforma open-source de prototipagem eletrônica com hardware e software flexíveis e fáceis de usar.

Para analisar a coloração da urina, utilizarmos o sensor RGB TCS34725. O sensor possui a função de ler percentuais de tonalidades de vermelho, azul e verde. Como resultado, obtém-se uma faixa de valores a qual corresponderá a cada tonalidade da urina, para saber se ela está dentro do padrão normal, detectando, assim, anomalias.

Já para medir o volume de urina, foi confeccionado um pluviômetro de báscula. Foi inspirado a partir de um aparelho meteorológico, sendo este utilizado para medir o volume e, consequentemente, o fluxo da urina. Funciona através de uma chave óptica, que opera detectando a quantidade de vezes que a báscula vira de lado, esvaziando seu conteúdo preenchido com $30 \mathrm{ml}$ de urina expelida pelo usuário.

Por último, para exibição das informações recolhidas e processadas pelo sistema do Mictório fez-se o uso de um display, componente que terá maior interação com o usuário. A Figura 1 mostra o protótipo do IMIC com todos os seus componentes.

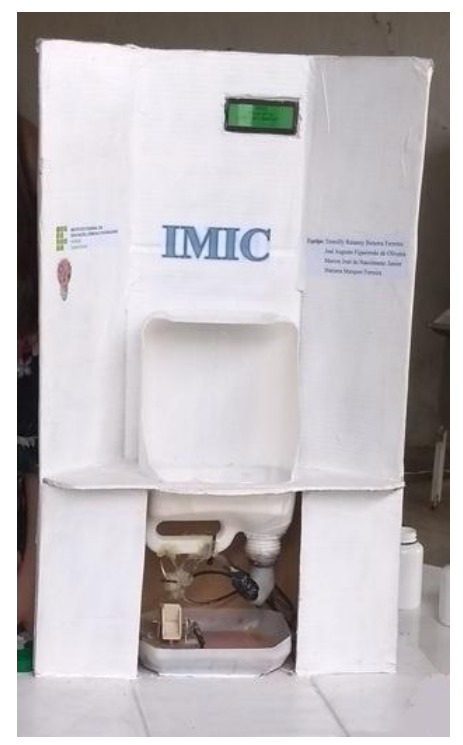

Figura 1: Protótipo IMic, feito a partir de objetos reciclados.

\section{Resultados e Discussão}

Como o IMic ainda é um protótipo,o qual está sendo utilizado para fins de testes em uma solução de água com corantes nas tonalidades de cor clara de ovo - bem próxima a cor da urina de uma pessoa considerada saudável - até a coloração avermelhada, esta última que representa a urina com quantidades de hemoglobina, sendo liberadas pelo sistema urinário, provocada por alguma desordem no organismo do usuário.

Foram definidos cinco padrões de urina que é a Urina Transparente com a cor clara de ovo, amarelo clara, amarelo escuro e, por último, a urina com Hemoglobina na 
cor avermelhada. Os resultados podem variar de pessoa para pessoa, porque o sistema também está calculando o tempo em que ela passa urinando e somente, desse modo, calcula o fluxo. Para verificar esse dado, este resultado está baseado no estudo de Sogari, et. al (2000), os quais analisam as variações normais do fluxo urinário máximo masculino em diferentes faixas etárias. Para a idade de 14 a 65 anos, o volume mínimo é de $200 \mathrm{ml}$ e o fluxo de 12 a $21 \mathrm{ml} / \mathrm{s}$.

\section{Trabalhos Futuros}

Para auxiliar o usuário a interpretar melhor os dados e guardá-los para fins de entendimento do seu próprio sistema renal, intenciona-se, como planos futuros, desenvolver um aplicativo para celular, um sistema de comunicação e uma interface de identificação através de RFID (implantado no crachá do usuário). Este sistema será capaz de armazenar os dados recolhidos toda vez que o homem for ao banheiro e ficarão disponíveis para serem interpretados até mesmo por um profissional da área de saúde.

Para aperfeiçoamento da análise feita pelo sistema do IMic, pretende-se acrescentar um medidor de $\mathrm{pH}$, o qual terá a finalidade de analisar a acidez da urina, pois se estiver muito ácida ou básica demais, significa que algo não está normal.

\section{Agradecimentos}

Agradecemos aos Professores do IFPB, que nos ajudaram com os desafios que apareceram ao decorrer deste projeto. Aos colegas do IFPB, por ajudarem a melhorar nossas ideias. A Professora Araceli Sobreira Benevides pela revisão de linguagem.

\section{Referências}

INCA. Próstata. Disponível em: <http://www2.inca.gov.br/wps/wcm/connect/ tiposdecancer/site/home/prostata> acesso em: 13 de março de 2018.

Klein, E. A.; Platz, E. A.; Thompson, I. M.. Epidemiology, etiology, and prevention of prostate cancer. In: WEIN, A. J. et al. (Ed.). Campbell-Walsh urology. 9th ed. Philadelphia: Saunders Elsevier, 2007. p. 2854-2857.

Sogari, P.; Dambros, M.; Souto, C. A. V.. Avaliação urodinâmica do homem com obstrução não neurogênica do trato urinário inferior. Revista AMRIGS, Porto Alegre, v.44, n.3,4: p.159-163, 2000.

Souza, A. R. A.; Almeida, S. S.; Oliveira, D. C. Análise estatística do câncer de próstata por meio da regressão logística. Revista Brasileira Biomedicina, São Paulo, v.31, n.3, p.441-448, 2013.

Tonon, T.; Schoffen, J.. Câncer de próstata: uma revisão da literatura. Revista Saúde e Pesquisa. v. 2, n. 3, p. 403-410, set./dez. 2009. 